\title{
Reconstitution of initial steps of dsDNA break repair by the RecF pathway of $E$. coli
}

\author{
Naofumi Handa, ${ }^{1,2,4,5}$ Katsumi Morimatsu, ${ }^{1,2,4}$ Susan T. Lovett, ${ }^{3}$ and Stephen C. Kowalczykowski ${ }^{1,2,6}$ \\ ${ }^{1}$ Department of Microbiology, University of California at Davis, Davis, Calfironia 95616, USA; ${ }^{2}$ Department of Molecular and \\ Cellular Biology, University of California at Davis, Davis, Calfironia 95616, USA; ${ }^{3}$ Rosenstiel Basic Medical Sciences Research \\ Center, Department of Biology, Brandeis University, Waltham, Massachusetts 02454, USA
}

\begin{abstract}
The RecF pathway of Escherichia coli is important for recombinational repair of DNA breaks and gaps. Here we reconstitute in vitro a seven-protein reaction that recapitulates early steps of dsDNA break repair using purified RecA, RecF, RecO, RecR, RecQ, RecJ, and SSB proteins, components of the RecF system. Their combined action results in processing of linear dsDNA and its homologous pairing with supercoiled DNA. RecA, RecO, RecR, and RecJ are essential for joint molecule formation, whereas SSB and RecF are stimulatory. This reconstituted system reveals an unexpected essential function for RecJ exonuclease: the capability to resect duplex DNA. RecQ helicase stimulates this processing, but also disrupts joint molecules. RecO and RecR have two indispensable functions: They mediate exchange of RecA for SSB to form the RecA nucleoprotein filament, and act with RecF to load RecA onto the SSB-ssDNA complex at processed ssDNA-dsDNA junctions. The RecF pathway has many parallels with recombinational repair in eukaryotes.
\end{abstract}

[Keywords: DSB repair; Rad52 group; RecA; RecF; RecQ; recombination]

Supplemental material is available at http://www.genesdev.org.

Received January 12, 2009; revised version accepted April 8, 2009.

Breaks in DNA chains occur frequently in all organisms (Kuzminov 1999). If left unrepaired, these breaks can be lethal. Consequently, organisms have highly refined systems for repairing breaks in both ssDNA and dsDNA, involving both nonhomologous end-joining and recombinational DNA repair. In Escherichia coli, there are two interrelated pathways for recombinational DNA repair: the RecBCD and the RecF pathways (Clark and Low 1988; Lloyd and Low 1996; Amundsen and Smith 2003; Spies and Kowalczykowski 2005). In wild-type cells, the RecBCD pathway is responsible for the repair of dsDNA breaks (DSBs), whereas the RecF pathway is largely responsible for the repair of ssDNA gaps. Although mostly separate in function and possessing unique protein constituents, these pathways share some common components such as the RecA and SSB proteins, which promote homologous DNA pairing, and the RuvABC protein complex, which resolves Holliday junctions.

In contrast to the extensively characterized RecBCD pathway, recombinational DNA repair promoted by the RecF pathway is biochemically less well understood.

\footnotetext{
${ }^{4}$ These authors contributed equally to this work.

${ }^{5}$ Present address: Laboratory of Social Genome Sciences, Department of Medical Genome Sciences, Graduate School of Frontier Sciences, University of Tokyo, 4-6-1 Shirokanedai, Minato-ku, Tokyo 108-8639, Japan. ${ }^{6}$ Corresponding author.

E-MAIL sckowalczykowski@ucdavis.edu; FAX (530) 752-5939.

Article is online at http://www.genesdev.org/cgi/doi/10.1101/gad.1780709.
}

Genetic studies in E. coli have defined the RecF pathway as involving recA, recF, recG, recJ, recN, recO, recQ, $\operatorname{rec} R, \operatorname{ruv} A, \operatorname{ruv} B, \operatorname{ruvC}, s s b, u v r D$, and helD functions (Kuzminov 1999). RecF, when acting in concert with RecR and RecO (the RecFOR complex), binds to the 5'end of an ssDNA gap and loads RecA onto the ssDNA (Morimatsu and Kowalczykowski 2003). RecO and RecR, in the absence of RecF, bind to the SSB-ssDNA complex and assist RecA in the displacement of SSB from the ssDNA (Umezu et al. 1993; Umezu and Kolodner 1994). These mediator functions facilitate RecA nucleoprotein filament formation and subsequent homologous pairing. RecG is a multifunctional DNA motor protein that can promote extension of heteroduplex DNA, regression of replication forks, and disruption of joint molecules (Briggs et al. 2004). RecJ is a $5^{\prime} \rightarrow 3^{\prime}$ ssDNA exonuclease that stimulates DNA strand exchange by degradation of the displaced ssDNA strand and, in addition, is hypothesized to function early in recombination at the DNA processing step (Lovett and Clark 1984; Corrette-Bennett and Lovett 1995). RecQ is a $3^{\prime} \rightarrow 5^{\prime}$ DNA helicase that can unwind duplex DNA to initiate homologous pairing, can disrupt nascent joint molecule, and also can act in concert with topoisomerase III to decatenate DNA duplexes (Umezu et al. 1990; Harmon and Kowalczykowski 1998; Harmon et al. 1999, 2003). The biochemical function of the E. coli RecN protein is unknown; however, in Bacillus subtilis, RecN protein acts to bridge the 
two ends of a dsDNA break (Sanchez and Alonso 2005; Sanchez et al. 2006). Finally, uvrD and helD encode DNA helicases II and IV, respectively (Mendonca et al. 1993; Lovett and Sutera 1995).

For many years, the RecF pathway was thought to be a "minor" pathway because recombination was mainly studied using biological processes that initiated using dsDNA breaks (e.g., conjugation, transduction, or phage crosses) and, hence, such recombination events were seen to depend only on the RecBCD pathway (Kuzminov 1999; Spies and Kowalczykowski 2005). However, in wild-type cells, the RecF pathway is responsible for all postreplication recombinational repair occurring at ssDNA gaps; e.g., repair of daughter strand gaps that remain after incomplete DNA replication on imperfect templates (Howard-Flanders 1975; Kuzminov 1999). This repair requires the RecA and RecFOR proteins, and both RecJ and RecQ to degrade the nascent lagging strand at the stalled replication fork (Courcelle and Hanawalt 1999). In addition, if RecBCD is inactivated, the RecF pathway is required for conjugational recombination, showing that it is fully capable of promoting recombinational DSB repair (Horii and Clark 1973; Lovett and Clark 1984; Nakayama et al. 1984; Kolodner et al. 1985; Mahdi and Lloyd 1989), provided that two mutations, called $s b c B$ (suppressor of $\operatorname{rec} B C$ ) and $s b c C$ (or $s b c D$ ), are present (Lloyd et al. 1987a,b). sbcB is a mutation in exonuclease I, which is normally a processive 3 '-specific ssDNA exonuclease (Kushner et al. 1972); the mutant exonuclease I binds ssDNA, displays reduced nuclease activity, and consequently protects the 3 '-end of the processed ssDNA from exonuclease VII (Viswanathan et al. 2000; Thoms et al. 2008). The $s b c C$ and $s b c D$ genes encode an nuclease, SbcCD (Connelly and Leach 1996), that might remove the $\mathrm{SbcB}$ proteins by endonucleolytically cleaving the ssDNA. Alternatively, the RecF pathway can operate on DSBs in cells that are deleted for both 3 '-specific ssDNA exonucleases, exonuclease I and exonuclease VII (Viswanathan et al. 2000). In such cells, recombination occurs at wild-type levels or higher, showing that the recombination enzymes of the RecF pathway are fully capable of promoting recombination from DSBs without the need for RecBCD enzyme or any suppressor mutations (Horii and Clark 1973; Lovett and Clark 1983; Lloyd et al. 1987a; Luisi-DeLuca et al. 1989). Furthermore, the RecF system is the major pathway for recombinational repair of all DNA breaks, both ssDNA gaps and DSBs, in prokaryotic organisms that lack RecBCD homologs (Rocha et al. 2005). Finally, organisms such as B. subtilis use both the RecF- and RecBCD-like systems for DSB processing and repair (Kidane and Graumann 2005; Sanchez et al. $2006,2007)$. Thus, the RecF pathway can promote recombinational repair of dsDNA breaks as well as ssDNA gaps (Michel et al. 2007).

Interestingly, it has become evident recently that the RecF pathway has many homologs in eukaryotic recombinational DNA repair. For example, RecO resembles Rad52 with regard to both mediator function and its ability to anneal ssDNA with its cognate SSB/RPA (Kantake et al. 2002). Another similarity concerns the RecFOR mediator complex: It functions by loading RecA onto ssDNA complexed with SSB (Morimatsu and Kowalczykowski 2003), and defects in this loading pathway can be suppressed by mutations in RecA (e.g., the RecA803 or RecA730 proteins) that enhance self-assembly on ssDNA (Madiraju and Clark 1990; Madiraju et al. 1992; Wang et al. 1993). This behavior is paralleled in Saccaromyces cerevisiae (Fortin and Symington 2002), where a hyperactive mutant Rad51 was shown to partially suppress the need for the mediator function of the Rad55/57 complex (Sung 1997), suggesting that RecFOR and Rad55/57 mediator complexes could be functional homologs. Similarly, RecQ helicase is not only the founding member of the structurally similar eukaryotic family of RecQ helicases (Nakayama et al. 1984; Wu and Hickson 2006), but it can both disrupt joint molecules (Harmon and Kowalczykowski 1998) and stimulate decatenation of DNA by topoisomerase III (Harmon et al. 1999), as can the human BLM helicase (Wu and Hickson 2003; Bugreev et al. 2007).

Previously, our laboratory examined DNA pairing initiated by RecQ and promoted by RecA and SSB in vitro (Harmon and Kowalczykowski 1998). Because RecQ is incapable of loading RecA onto ssDNA that is complexed with SSB, in vitro reactions required a molecular crowding reagent to facilitate RecA-loading and homologous pairing. Recently, however, we discovered that the RecFOR proteins would load RecA protein onto ssDNA at the junction between ssDNA and dsDNA (Morimatsu and Kowalczykowski 2003), suggesting that RecFOR could provide the needed loading function. Finally, the behavior of RecJ in the initiation of DNA pairing has not been examined. Here, we describe a concerted sevenprotein reaction involving $\mathrm{RecA}$, $\mathrm{RecF}, \mathrm{RecO}, \mathrm{RecR}$, RecQ, RecJ, and SSB proteins that can resect linear dsDNA to promote joint molecule formation between the resulting processed ssDNA-tailed duplex DNA and homologous supercoiled dsDNA (scDNA). Our findings reveal that RecJ exonuclease, which has repeatedly been proposed to act as an ssDNA exonuclease on the 5'terminated ssDNA created by the unwinding activity of RecQ helicase, has the unanticipated function of resecting duplex DNA mediated independently of RecQ helicase. Our results provide many potential parallels for understanding the functions of eukaryotic homologs, such as Rad51, the Rad51 paralogs, Rad52, the RecQ helicases, and Exonuclease 1 in the repair of DNA breaks.

\section{Results}

Joint molecule formation promoted by RecA, RecF, $\operatorname{Rec} O, \operatorname{Rec} R, \operatorname{Rec}, \operatorname{RecQ}$, and SSB proteins

As mentioned earlier, the RecF pathway is fully proficient in the recombinational repair of DNA breaks. To understand the biochemical mechanism of this process, formation of joint molecules between two duplex DNA substrates was examined in vitro. Because joint molecule formation requires processing of one duplex substrate to reveal ssDNA before it can be used for RecA-promoted 
invasion of homologous supercoiled DNA (scDNA), this strategy defines proteins that are essential for both processing and homologous DNA pairing (Dixon and Kowalczykowski 1991; Harmon and Kowalczykowski 1998, 2000). Similar to an earlier study (Harmon and Kowalczykowski 1998), we used linear plasmid DNA (3' end-labeled) and homologous supercoiled dsDNA; exonucleolytic resection and/or DNA unwinding will produce ssDNA that can then be used for homologous pairing with the supercoiled DNA to produce a joint molecule (JM in Fig. 1A). However, in contrast to the prior study, volume excluding agents were not used to enhance RecA nucleoprotein assembly and DNA pairing nor were conditions optimal for RecQ-dependent unwinding of dsDNA; instead, the RecF, $\mathrm{RecO}$, and RecR proteins were added to determine whether they could coordinate RecA nucleoprotein filament assembly on the newly created ssDNA (Morimatsu and Kowalczykowski 2003).

When RecA, RecF, RecO, RecR, RecJ, RecQ, and SSB were added to these DNA substrates at concentrations similar to those used previously (Harmon and Kowalczykowski 1998; Morimatsu and Kowalczykowski 2003), joint molecules were readily formed (Fig. 1B; Supplemental Fig. 1; linear pUC19 dsDNA and supercoiled pUC1950 DNA have nearly identical electrophoretic mobilities). The joint molecules are detected within
$10 \mathrm{~min}$, and the optimal yield $(\sim 20 \% \pm 10 \%$ of the input labeled linear dsDNA) occurs generally after about 30 min, after which a slight increase or decrease is sometimes observed, depending on reaction conditions (see below). As expected, DNA pairing requires both ATP and homology (Supplemental Fig. 1): If either the homologous supercoiled DNA is omitted, or nonhomologous $\phi \mathrm{X} 174$ supercoiled DNA is substituted (Supplemental Fig. 2), then no joint molecules are detected. In all cases, processing of the linear dsDNA nonetheless still occurs, as evidenced by the smear of faster migrating DNA molecules below the position of the intact linear dsDNA substrate; the annealing of this processed DNA sometimes leads to trace amounts of products that run above the position of linear dsDNA. Note also that when the scDNA is omitted (Supplemental Fig. 1), the yield of processed dsDNA appears to increase because the processed DNA that would have been part of the joint molecule is now added to the processed DNA below the full-length linear dsDNA position.

To verify that the joint molecules are indeed the products of pairing between the processed linear dsDNA and the supercoiled recipient, the size of the supercoiled target DNA was changed. When smaller pUC19 $(2.7 \mathrm{~kb})$ is used as the supercoiled partner instead of pUC1950 (4.6 $\mathrm{kb}$ ), also permitting visualization of the linear pUC19
A

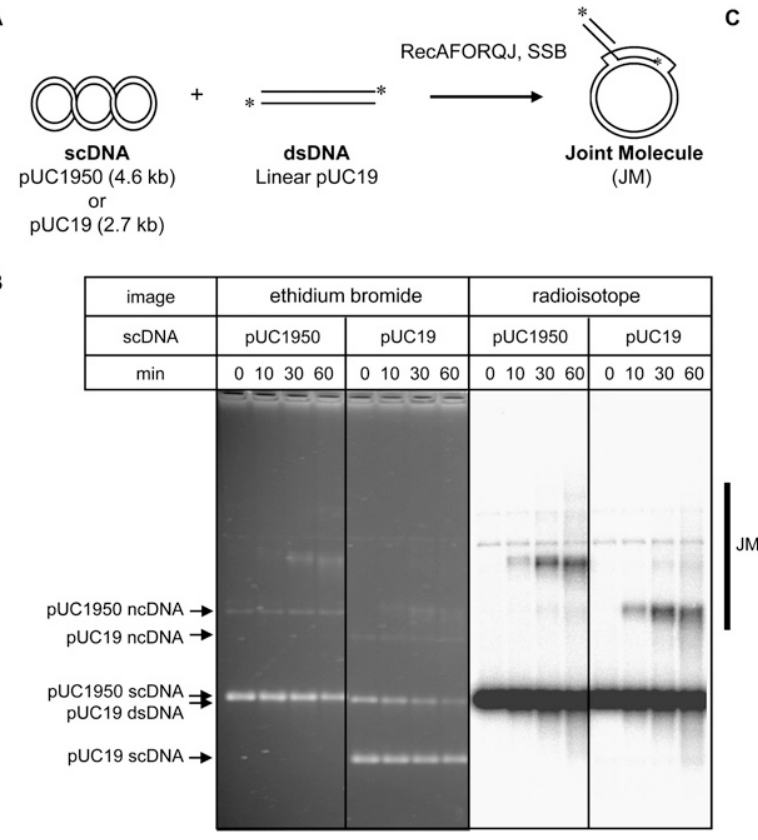

c

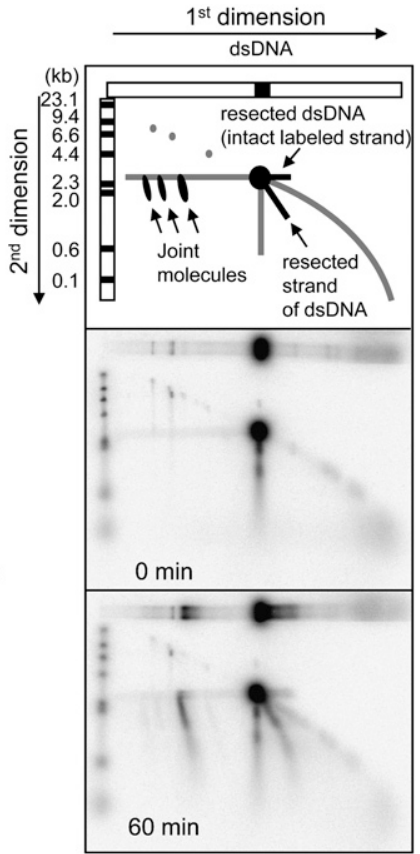

Figure 1. Joint molecule formation by coordinated action of RecA, RecF, RecO, RecR, RecQ, Rec), and SSB proteins. (A) Reaction scheme: 3'-end-labeled linear dsDNA ("dsDNA" and homologous supercoiled DNA ("scDNA") are used as substrates. DNA processing and homologous pairing produce joint molecules ("JM") that are detected by agarose gel electrophoresis. $(B)$ Reactions with either pUC1950 or pUC19 (as indicted) as the scDNA. The scDNA was $20 \mu \mathrm{M}$ (nucleotides) to permit comparison with $C$. Due to the lower scDNA concentration, the product yield was $10 \%$ for pUC1950 and $8 \%$ for pUC19 at $60 \mathrm{~min}$. (Left two panels) Ethidium bromide staining. (Right two panels) Radioisotopic imaging of 3'-end-labeled EcoRI-digested linear dsDNA. (C) Two-dimensional gel electrophoresis of reaction products. DNA was analyzed by native gel electrophoresis in the first dimension; one of two replicate lanes is shown at the top. The other gel slice was subjected to electrophoresis in a second dimension using denaturing conditions. The illustration shows the reaction products, which are indicated by arrows; the other spots are nonspecific background contaminants present at time 0 . From right to left, the yield of joint molecule products is $6.8 \%, 0.5 \%$, and $0.2 \%$. 
dsDNA in the ethidium bromide stained gel, the sizes of the joint molecules decrease accordingly (Fig. 1B). Depending on reaction time and conditions, up to three joint molecule product species can be resolved. The most abundant is the fastest migrating joint molecule, which has a mobility consistent with invasion by one resected dsDNA molecule. The next most abundant joint molecule has a slower mobility consistent with being composed of three DNA molecules; this species is likely a mixture of resected linear dsDNA paired at both ends with scDNA, and scDNA invaded by two resected linear DNA molecules because this product is also evident when 5 '-end-labeled linear DNA is used (Supplemental Fig. 1). The faintest and slowest joint molecule is an undefined complex structure likely comprising four DNA molecules.

The products of this reaction were also analyzed by two-dimensional gel electrophoresis (Fig. 1C shows 0 -min and 60-min reactions; the full time course is provided in Supplemental Fig. 3). In the first dimension (running from left to right), electrophoresis was performed in neutral conditions, as in Figure 1B. In the second dimension (running from top to bottom), electrophoresis was performed in alkaline conditions to denature all DNA into individual DNA strands. Due to resection of the linear 3 '-end-labeled dsDNA, all of the products run as smeared bands, which are identified in the illustration at the top. Processing of the linear dsDNA produces two resected products in the $2 \mathrm{D}$ profile. The product labeled as "resected strand of dsDNA" migrates as resected dsDNA in the first dimension. When run in the second dimension, comparison with the size markers reveals that the resected strand is as short as $0.5-1 \mathrm{~kb}$, indicating resection of $1.7-2.2 \mathrm{~kb}$. For the majority of the DNA, resection is limited to about 700 bases. In the product labeled "resected dsDNA (intact labeled stand)," only one strand of the dsDNA is resected so that the single-ended resection product migrated faster in the first dimension but, after denaturation, the unresected strand migrates as full-length ssDNA in the second dimension. Three joint molecule products, whose migration in the first dimension is slower than that of the resected dsDNA, are readily discerned. The major species is the fastest migrating in the first dimension; in the second dimension, this joint molecule contains a strand with the same mobility as the "resected strand of dsDNA," indicating that the joint molecules contains resected linear DNA.

Joint molecule formation requires $\operatorname{Rec} A, \operatorname{RecO}$, RecR, and RecI proteins, and is stimulated by $S S B$ and RecF proteins

To determine the importance of the proteins in this homologous pairing process, each was omitted from the complete reaction (Fig. 2). It is readily evident that when either RecO, RecR, RecA, or RecJ is omitted (reactions 4, 5,6 , and 7, respectively), joint molecule formation is completely eliminated. A RecA titration showed that joint molecule formation saturated at $\sim 2.5 \mu \mathrm{M}$, and declined monotonically by $\sim 50 \%$ when the RecA concentration was reduced to $0.25 \mu \mathrm{M}$ (Supplemental Fig. 4). When RecO, RecR, or RecA is omitted, the failure to produce joint molecules was clearly not due to a failure to process the linear dsDNA substrate (reactions 4, 5 , and 6), because resection and/or unwinding of the linear dsDNA is evident in all three time courses. In contrast, when RecJ is omitted (reaction 7), not only is joint molecule formation eliminated, but processing of dsDNA is also eliminated, showing that neither resection nor unwinding into full-length ssDNA occurred in the absence of RecJ. These findings imply that the mediator function of RecOR, the DNA pairing activity of RecA, and an exonucleolytic processing ability of RecJ are all essential for joint molecule formation under these conditions.

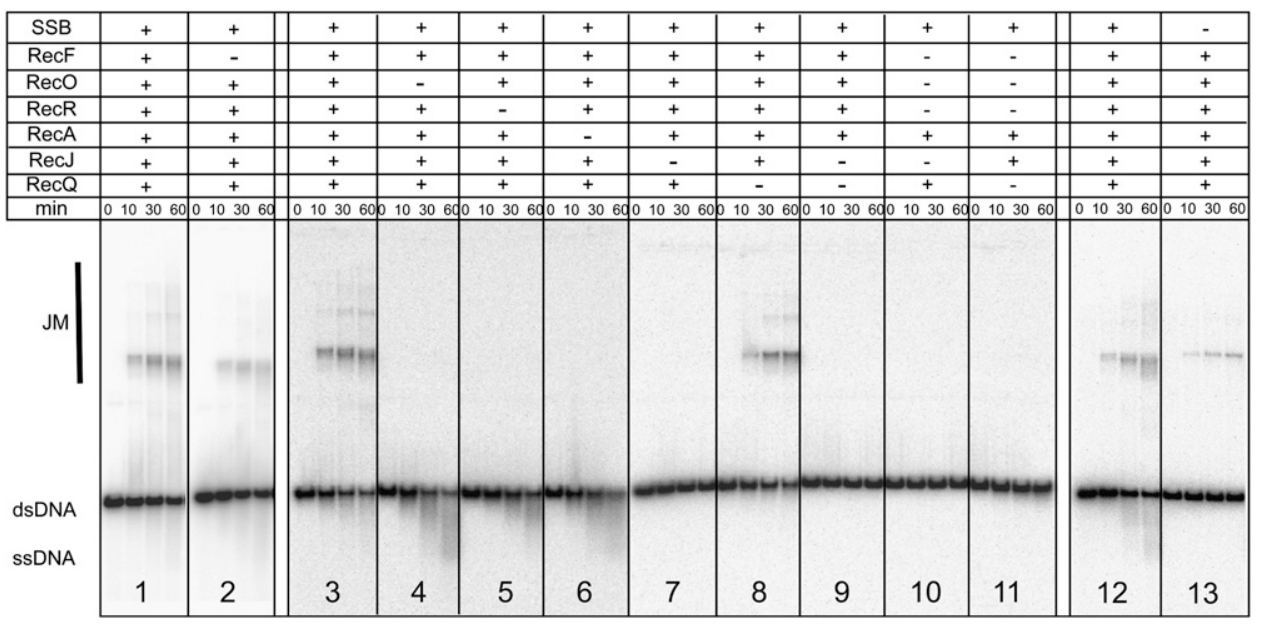

Figure 2. Homologous DNA pairing requires $\mathrm{RecA}, \mathrm{RecO}, \mathrm{RecR}$, and RecJ proteins and is stimulated by RecF and SSB proteins. Proteins present are indicated at the top of the gel. The complete reaction is shown in three reaction time courses (reactions 1, 3, and 12) to permit direct comparison to the adjacent reactions (reactions 2, 4-11, and 13, respectively), which were performed at the same time. From left to right, the yield of joint molecules at $60 \mathrm{~min}$ for these reactions is $19 \%, 10 \%, 32 \%, 0 \%, 0 \%, 0 \%, 0 \%, 36 \%, 0 \%, 0 \%, 0 \%$, $15 \%$, and $3 \%$. 
Though not essential, omission of SSB reduces joint molecule formation by fivefold to 10-fold (Fig. 2, reaction 13). An SSB titration revealed that $\sim 3 \mu \mathrm{M}$ was optimal (Supplemental Fig. 5). Resection was not evident when SSB was omitted (reaction 13), even though some joint molecules were formed; however, as will be shown elsewhere, higher-resolution gels show that resection by RecJ is indeed occurring, but SSB greatly stimulates the resection of dsDNA (K Morimatsu, $\mathrm{N}$ Handa, and SC Kowalczykowski, unpubl.). Clearly, the ssDNA-binding capacity of SSB is important for both DNA resection and homologous pairing.

When RecF is omitted, the yield of joint molecules is reduced by about half but is not eliminated (Fig. 2, reaction 2). Changing the $\mathrm{RecF}$ protein concentration from 5 to $100 \mathrm{nM}$ did not change the yield of joint molecules relative to the standard concentration of 15 $\mathrm{nM}$ (data not shown), showing that the standard reaction is not suboptimal with regard to RecF function. The finding that RecF omission reduces the yield of joint molecules by $\sim 50 \%$ suggests that, at these conditions, RecA is being loaded onto the SSB-ssDNA complexes by RecFOR at only approximately half of the processed DNA duplexes; for the other half, RecA nucleoprotein filament formation is being facilitated by RecOR.

The RecQ helicase is also not essential for joint molecule formation (Fig. 2, reaction 8). The failure to

A.

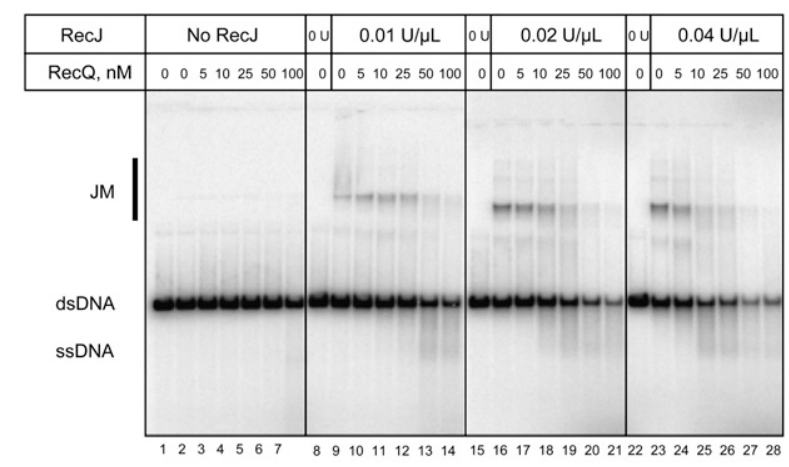

B.

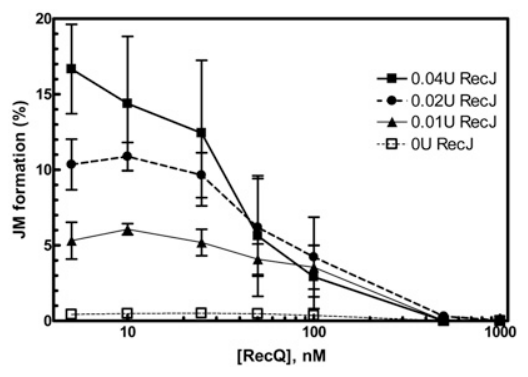

Figure 3. RecQ helicase stimulates dsDNA resection by RecJ nuclease but disrupts joint molecules. (A) Joint molecule formation as a function of RecQ at various RecJ concentrations (indicated at top of the gel) was assayed at $60 \mathrm{~min} .(B)$ Quantification of joint molecule formation expressed as the amount of product relative to the amount of linear dsDNA, which is limiting. Error bars represent the standard error from multiple experiments. see a strong dependence on RecQ is also not due to a suboptimal concentration, because increasing the RecQ concentration resulted in a progressive reduction in joint molecules, rather than an increase, until none were detected at concentrations exceeding $\sim 500$ nM (Fig. 3).

Experiments where several proteins are removed from the complete reaction confirm the essential role of RecOR and RecJ. When both of the potential processing enzymes, RecJ and RecQ, are omitted, joint molecules are not detected (Fig. 2, reaction 9). Similarly, when both the RecFOR complex and the nonessential RecQ helicase are omitted (reaction 11), joint molecule formation is not detected, despite the presence of some processing by RecJ exonuclease. Likewise, when only RecA, RecQ, and SSB proteins are present (reaction 10), in the absence of a molecular crowding agent, they do not promote any DNA pairing, as previously reported (Harmon and Kowalczykowski 1998).

Finally, to determine whether the reaction is concerted, the complete reaction was compared with a reaction in which the linear dsDNA was first processed in the presence of RecJ, RecQ, and SSB proteins, with or without RecFOR; then the resected DNA was isolated; and, finally, RecA, SSB, and scDNA were subsequently added with or without added RecFOR (Fig. 4). In these uncoupled reactions, joint molecules are not formed efficiently due to the slow rate of SSB displacement without the continued presence of the mediators, suggesting that coordination between resection and RecA loading is important for efficient homologous pairing. Thus, we established concerted joint molecule formation in vitro that is dependent on $\mathrm{RecA}, \mathrm{RecO}, \mathrm{RecR}$, and RecJ, and where resection and/or DNA pairing is stimulated by RecF, RecQ, and SSB; for simplicity, we will refer to this reaction as the RecAFORQJ reaction.

\section{RecI is needed for DNA resection, and RecQ stimulates resection but disrupts joint molecules}

It was known from a previous study that the role of RecQ helicase in concerted DNA pairing reactions is complex: At low concentrations, RecQ can unwind the linear dsDNA to produce a ssDNA substrate for RecA protein, but at high RecQ concentrations, it can disrupt joint molecules, reducing joint molecule yield (Harmon and Kowalczykowski 1998). The function of RecQ was consequently more carefully investigated in the more complex RecAFORQJ reaction (Fig. 3). At the lower concentrations of RecJ $(0.01$ and $0.02 \mathrm{U} / \mu \mathrm{L})$, increasing the concentration of RecQ to $10 \mathrm{nM}$ has little effect on joint molecule formation, but increasing the RecQ concentration further results in a pronounced decrease (Fig. 3B). However, it is also evident from Figure $3 \mathrm{~A}$ that RecQ facilitates processing of the linear dsDNA by RecJ exonuclease, demonstrating that the reduction in joint molecule formation is not due to a failure to produce ssDNA. In fact, increasing concentrations of RecQ actually increase the amount of DNA degraded by RecJ (e.g., Fig. 3, lanes 16-21). When the time course of joint molecule formation is monitored (Supplemental Fig. 6), it is clear 


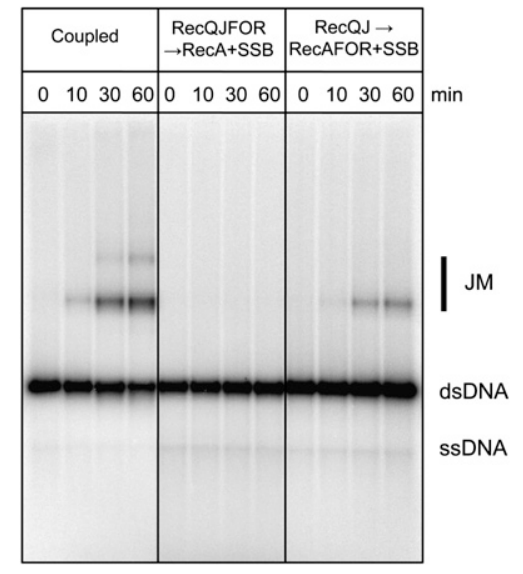

Figure 4. DNA pairing in the RecAFORQJ reaction is concerted. (Left panel) The standard reaction conditions were used for the "Coupled" reaction. (Middle panel) In one uncoupled reaction (labeled "RecQJFOR $\left.\rightarrow \operatorname{Rec} A+\mathrm{SSB}^{\prime}\right)$, the linear dsDNA was incubated with RecFOR, RecQ, RecJ, and SSB for $30 \mathrm{~min}$, ethanol precipitated, and then suspended in reaction buffer at the same DNA concentration; a mixture of RecA and SSB was added, followed by the scDNA, and then incubated for the times indicated. In the right panel ("RecQJ $\rightarrow$ RecAFOR + $\mathrm{SSB}^{\prime \prime}$ ), the linear dsDNA was incubated with RecQ, RecJ, and SSB for $30 \mathrm{~min}$, ethanol precipitated, and then suspended; a mixture of RecFOR, RecA, and SSB was added, followed by the scDNA. The yield of joint molecules at $60 \mathrm{~min}$ is $20 \%, 0 \%$, and $5 \%$, respectively.

that even at the inhibitory concentrations of RecQ (e.g., $100 \mathrm{nM})$, joint molecules are formed at early times, but are subsequently dissociated. Raising the concentration of RecJ results in increased dsDNA degradation that is more apparent when RecQ is present (Fig. 3, lanes 23-28).

Interestingly, in the absence of RecJ nuclease, there is no joint molecule formation, and this failure cannot be compensated by any amount of RecQ examined (Fig. 3B). Although the DNA unwinding activity of RecQ is limited under these conditions (Harmon and Kowalczykowski 2001), some unwinding is detected at the highest RecQ concentrations tested (Fig. 3A, lane 7; data not shown); however, the potent joint molecule disruption capacity of RecQ could preclude accumulation of joint molecules (Harmon and Kowalczykowski 1998). Thus, we conclude that, although RecQ helicase can stimulate the processing of linear dsDNA by RecJ, by itself, RecQ does not promote joint molecule formation under these conditions. Therefore, RecJ is indispensable, revealing that exonucleolytic resection of the duplex DNA by RecJ, rather than the ssDNA, is an essential step in this concerted reaction.

The RecOR proteins serve two essential functions: mediating exchange of RecA for SSB on the SSDNA, and loading of RecA by RecFOR onto SSB-SSDNA at its junction with dsDNA

Previous studies established that the RecFOR complex needs to bind to the junction between ssDNA and dsDNA of resected or gapped DNA to load RecA (Morimatsu and
Kowalczykowski 2003). In contrast, the RecOR proteins act in a stoichiometric complex with SSB-ssDNA to mediate the assembly of a RecA nucleoprotein filament (Umezu et al. 1993; Umezu and Kolodner 1994). To reveal the function of RecF when it was acting in conjunction with RecOR, it was necessary to use limiting amounts of RecOR relative to the SSB-ssDNA complex (Morimatsu and Kowalczykowski 2003). However, in the concerted RecAFORQJ reaction, the quantity of ssDNA produced is unknown. Consequently, to determine whether RecF function in this reaction was being obscured by RecORmediated assembly of the RecA nucleoprotein filament, the concentrations of $\mathrm{RecO}$ and RecR were reduced and varied independently (Fig. 5). A RecO titration was performed both in the presence and absence of RecF, initially using the standard concentration of RecR. The results (Fig. 5A,B) show that below $30 \mathrm{nM}$ RecO, RecF marginally (1.3-fold) stimulates joint molecule formation but, at the higher concentrations, RecF actually inhibits the reaction. However, when the $\mathrm{RecO}$ concentration is reduced to $15 \mathrm{nM}$, significant stimulation by RecF is evident (Fig. 5C). At $15 \mathrm{nM} \mathrm{RecO}$, RecF stimulates DNA pairing at all concentrations of RecR examined, and the magnitude of this stimulation is greatest at the lowest RecR concentrations (Fig. 5D). Although the yield of joint molecules is reduced by about half due to reduction of RecOR-mediated loading of RecA onto ssDNA, stimulation by RecF at these reduced concentrations of $\mathrm{RecO}$ and RecR is $\sim 10$ fold. A time course of joint molecule formation reveals a clear dependence of RecF at this lowered RecOR protein concentration (Supplemental Fig. 7).

Because the RecFOR proteins are required only when SSB protein limits assembly of RecA on ssDNA (Umezu and Kolodner 1994; Morimatsu and Kowalczykowski 2003), we expected that the residual DNA pairing seen in the absence of SSB (Fig. 2, reaction 13) should be independent of RecFOR because the omission of SSB should preclude the need for any RecA-loading function. Indeed, when SSB is omitted from the concerted reactions, the remaining joint molecule formation is still RecA- and RecJ-dependent, but no longer dependent on RecFOR (Supplemental Fig. 8); only RecA and RecJ are needed for DNA pairing (data not shown). These results show that the RecF, RecO, and RecR proteins are essential to mediate the loading of RecA onto ssDNA only when it is complexed with SSB. Collectively, our findings are consistent with the conclusion that the RecOR complex stimulates joint molecule formation via two distinct mechanisms: (1) by binding to SSB-ssDNA complexes to mediate RecA nucleoprotein filament assembly, and (2) by interacting with RecF protein to bind the ssDNA-dsDNA junction of the resected DNA and then to load RecA onto the SSB-complexed ssDNA tail.

The hyperactive RecA730 protein suppresses the need for RecF, RecO, and RecR proteins in RecAFORQJ-mediated joint molecule formation

Genetic studies established that the requirement for RecFOR proteins is partially suppressed by a class of 
Figure 5. The need for RecF protein in joint molecule formation becomes apparent at lower concentrations of the RecOR proteins. Reactions used the indicated $\mathrm{RecO}$ and $\mathrm{RecR}$ concentrations, and were for $60 \mathrm{~min}$. (A) The $\mathrm{RecO}$ concentration was varied from 0 to $100 \mathrm{nM}$ in the presence or absence of RecF at $1 \mu \mathrm{M}$ RecR. $(B)$ Quantification of joint molecule formation in $A$ expressed relative to the amount of linear dsDNA. $(C)$ The RecR concentration was varied from 0 to $1000 \mathrm{nM}$ in the presence or absence of RecF at $15 \mathrm{nM}$ RecO. (D) Quantification of joint molecule formation in $C$ expressed relative to the amount of linear dsDNA. Error bars represent the standard error.
A.
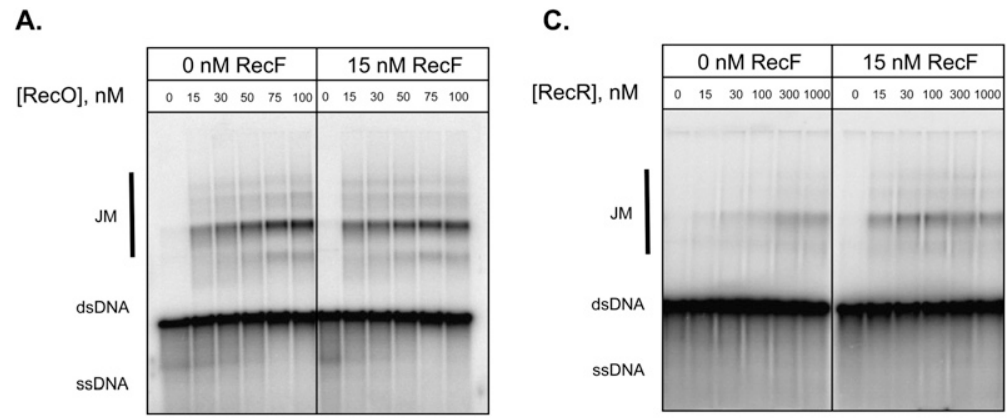

B.

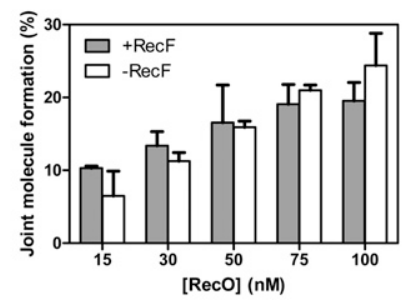

D.

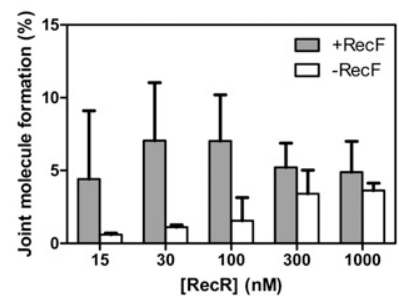

rec $A$ mutations ( $s r f$, or suppressor of $r e c F$ ) that produce proteins that assemble on ssDNA more rapidly than wildtype RecA (Madiraju et al. 1992). One of these suppressor proteins is the RecA730 protein (Lavery and Kowalczykowski 1992). Figures 2 showed that omission of RecFOR abolished joint molecule formation by wildtype RecA, but not dsDNA processing. However, Figure 6 shows that RecA730 can significantly restore joint molecule formation to a concerted reaction that lacks RecFOR, as expected from genetic and biochemical analyses. Joint molecule formation by RecA730 protein requires the exonucleolytic processing activity of RecJ, in agreement with another genetic finding (Thoms and Wackernagel 1988), and is stimulated by RecQ helicase. Thus, joint molecule formation by the concerted actions of RecA, RecF, RecO, RecR, RecJ, RecQ, and SSB proteins recapitulates the features expected based on in vivo analysis.

\section{Discussion}

Most of the biochemical properties of the individual proteins that comprise the RecF pathways of recombinational DNA repair have been defined, but their integration into a coordinated system for the repair of broken DNA had not yet been achieved. Here we described a concerted in vitro reaction involving RecA, RecF, RecO, RecR, RecQ, RecJ, and SSB proteins that leads to the production of joint molecules from linear dsDNA and homologous supercoiled DNA. Joint molecule formation requires the activities of $\mathrm{RecA}, \mathrm{RecO}, \mathrm{RecR}$, and $\mathrm{RecJ}$, and is stimulated by RecF and SSB. The strong dependence on RecOR is consistent with genetic results showing that the recombination deficiency of a $r e c R$ or $r e c O$ mutant strain is more severe than that bearing a recF mutation (Sawitzke and Stahl 1992). We also showed that RecJ is essential for, and that both RecQ and SSB stimulate, processing of linear duplex DNA into an intermediate containing ssDNA that is suitable for RecA nucleoprotein filament assembly. The essential role of RecJ was defined genetically when it was originally discovered (Lovett and Clark 1984). Unexpectedly, we discovered that the exonucleolytic resection of dsDNA, rather than the expected ssDNA, is an important function of RecJ. RecA, RecFOR, and SSB are needed for the homologous pairing phase of the reaction. The requirement for RecFOR can be bypassed by using a mutant RecA, RecA730, which has an intrinsically greater capacity to displace SSB from ssDNA and to self-assemble into a nucleoprotein filament. RecQ helicase was not essential for joint molecule formation, but it stimulated DNA processing by RecJ exonuclease. Finally, excess RecQ helicase disrupted joint molecules that formed, as was previously reported (Harmon and Kowalczykowski 1998); although seemingly contradictory, disruption of joint molecules is an important step in synthesis-dependent strand annealing mechanisms that permit recombinational DNA repair without chromosomal crossovers (Lovett and Sutera 1995; Allers and Lichten 2001; Hunter and Kleckner 2001). Our observations can be explained in the context of the model illustrated in Figure 7, which is discussed below.

The first step is processing of the linear (broken) duplex DNA into a substrate suitable for RecA-dependent homologous pairing. Despite a commonly held expectation that RecQ helicase would be needed to unwind the dsDNA into ssDNA that is the substrate for exonucleolytic processing by RecJ, which is an ssDNA-specific exonuclease, we discovered that RecQ helicase was stimulatory but not essential. Instead, resection is via a capacity of RecJ to degrade one strand of dsDNA (Han et al. 2006). These findings are, in fact, consistent with genetic analyses that established that mutation of $\mathrm{rec} /$ results in a greater reduction of recombination by the RecF pathway 


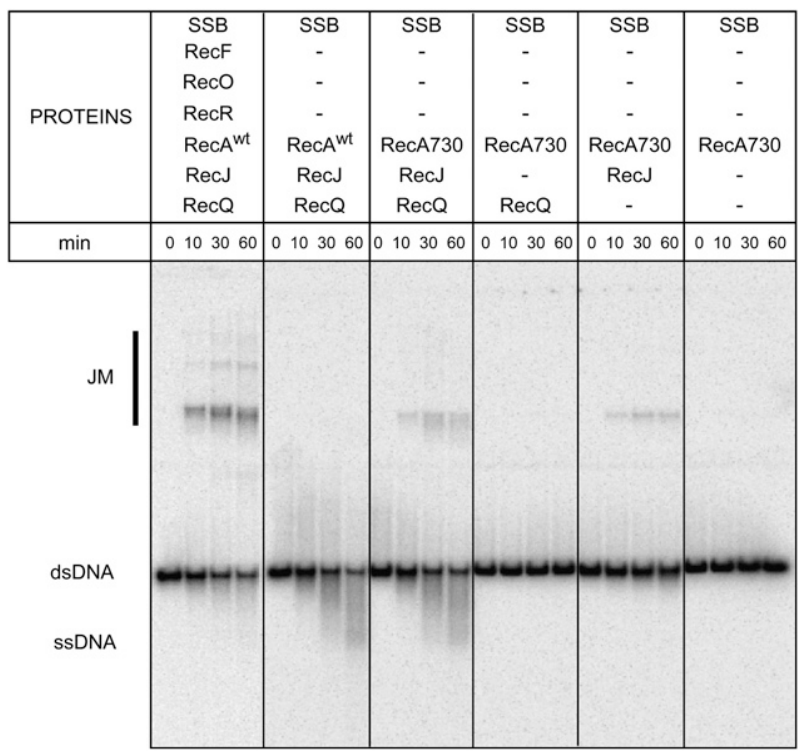

Figure 6. RecA730 protein can partially bypass the need for $\mathrm{RecF}, \mathrm{RecO}$, and RecR proteins. Proteins present are indicated at the top of the gel. From left to right, the yield of joint molecules at $60 \mathrm{~min}$ is $19 \%, 0 \%, 4 \%, 0 \%, 2 \%$, and $0 \%$.

than mutation of recQ (Luisi-DeLuca et al. 1989; Sawitzke and Stahl 1992); this in vivo observation could be a consequence of redundancy in helicase function provided by helicases II and IV (Mendonca et al. 1995). However, both RecQ and RecJ are needed for the DNA degradation that precedes replication fork resumption (Courcelle et al. 2003; Chow and Courcelle 2004), suggesting that the differences in DNA structure at a stalled fork or ssDNA gap versus a dsDNA break reveal differential needs for RecQ function in vivo; preliminary biochemical analyses of DNA resection by RecJ and RecQ are consistent with this view (K Morimatsu, N Handa, and SC Kowalczykowski, unpubl.).

RecJ exonuclease prefers ssDNA substrates with 5'tails that are longer than 7 nucleotides (nt); however, it does display a limited slower degradation of dsDNA that previously had been shown to extend $\sim 10 \mathrm{nt}$ into the duplex region of a tailed DNA substrate (Han et al. 2006). This finding indicates that RecJ has an intrinsic capacity to resect duplex DNA to produce 3 '-tailed ssDNA that is the ideal substrate for DNA strand invasion. Our observation that RecQ helicase stimulates processing by RecJ nuclease is consistent with this biochemical observation, and further suggests that DNA unwinding enhances DNA processing. It remains to be determined whether RecQ and RecJ synergistically cooperate in this process but our data here suggests, minimally, that RecQ stimulates turnover by RecJ (that is, more substrate is processed exonucleolytically when RecQ is present) and preliminary data suggest that RecQ helicase stimulates the processivity of RecJ nuclease (K Morimatsu, N Handa, and SC Kowalczykowski, unpubl.).

After DNA processing, RecA protein must assemble into a nucleoprotein filament on the ssDNA produced by resection. Earlier studies showed that SSB protein bound to ssDNA more rapidly than RecA, blocking the subsequent homologous pairing step (Kowalczykowski et al. 1987). However, this inhibition by SSB could be overcome by a number of mechanisms. The first to be discovered was the existence of mutant RecA proteins that are intrinsically better at nucleoprotein filament assembly (Volkert and Hartke 1984; Madiraju et al. 1992). The RecA730 protein is one such mutant (Lavery and Kowalczykowski 1992). These mutant RecA proteins were isolated as genetic suppressors of recF functions (Volkert and Hartke 1984); recA730 and other srf mutations that map to recA also suppress the UV sensitivity of recO or recR (and recF recR or recF recO) mutations to a similar degree as the recF mutation (Wang et al. 1993; Liu et al. 1998). Furthermore, this srf suppression is dependent on recJ function (Thoms and Wackernagel 1988; Wang et al. 1993). These observations are in full accord with our biochemical findings: RecA730 protein can load onto the resected ssDNA tail without the assistance of the RecA-loading proteins, RecFOR, but joint molecule formation, nonetheless, requires RecJ activity.

Wild-type E. coli cells use various mechanisms to facilitate RecA nucleoprotein filament formation through the use of RecA-loading proteins. In E. coli, there are three RecA-loading complexes: the RecBCD enzyme, the RecOR complex, and the RecFOR complex. The RecBCD enzyme loads RecA protein onto the $\chi$-containing ssDNA produced during the course of translocation and duplex DNA unwinding (Anderson and Kowalczykowski 1997). The RecOR complex mediates the exchange of RecA for SSB protein that is bound to ssDNA; optimal mediator activity requires a stoichiometric amount of $\mathrm{RecO}$ relative to SSB (Umezu et al. 1993; Umezu and Kolodner 1994). The RecFOR complex loads RecA onto ssDNA at an ssDNA-dsDNA junction with a recessed 5'-duplex end (Morimatsu and Kowalczykowski 2003). We conclude that the requirement for RecOR in our reactions is to mediate the loading of RecA onto the ssDNA produced by RecJ (and RecQ and SSB). Mediation by RecOR does not require a specific DNA structure. We found that at low RecOR concentrations, DNA pairing was strongly $(\sim 10$ fold) dependent on RecF (Fig. 5D). Furthermore, with increasing RecOR concentration, the need for RecF was diminished, demonstrating that these proteins could compensate for RecF function in this in vitro reaction. Unfortunately, the intracellular concentrations of RecF, $\mathrm{RecO}$, and RecR proteins are unknown, so a direct comparison of in vivo and in vitro conditions is not possible. However, our biochemical findings are in qualitative agreement with genetic results: Overexpression of $r e c R$ in the presence of $r e c O$ was sufficient to partially suppress the loss of recF function by a mechanism that required recJ (Sandler and Clark 1994). These in vivo results are recapitulated in vitro and rationalize why all of the DNA pairing is dependent on both RecO and RecR, but only partially dependent on RecF protein. Thus, it appears that the intracellular concentrations of $\mathrm{RecO}$ and RecR are limiting, and equivalent to those used in our in 
Handa et al.

Figure 7. Model for dsDNA break repair by the proteins of the RecF pathway. The exonuclease activity of RecJ resects duplex DNA by degrading in the $5^{\prime} \rightarrow 3^{\prime}$ direction, stimulated by RecQ helicase and SSB. The resultant ssDNA tail is bound by SSB. (Left) The RecFOR complex binds at the ssDNA-dsDNA junction on the resected DNA, and loads RecA onto the ssDNA. (Right) The RecOR complex can also mediate exchange of RecA for SSB bound to ssDNA at sites away from the junction. The RecA-ssDNA nucleoprotein filament invades homologous recipient duplex DNA. RecJ can contribute to stabilization of the D-loop by degrading the displaced ssDNA after nicking (not shown) (Corrette-Bennett and Lovett 1995), whereas RecQ helicase may disrupt recombination intermediates by unwinding from $3^{\prime} \rightarrow 5^{\prime}$ direction. At this point (not shown), the joint molecule can be converted to a Holliday junction and resolved, or disrupted after DNA synthesis to anneal with the second end of a dsDNA break.

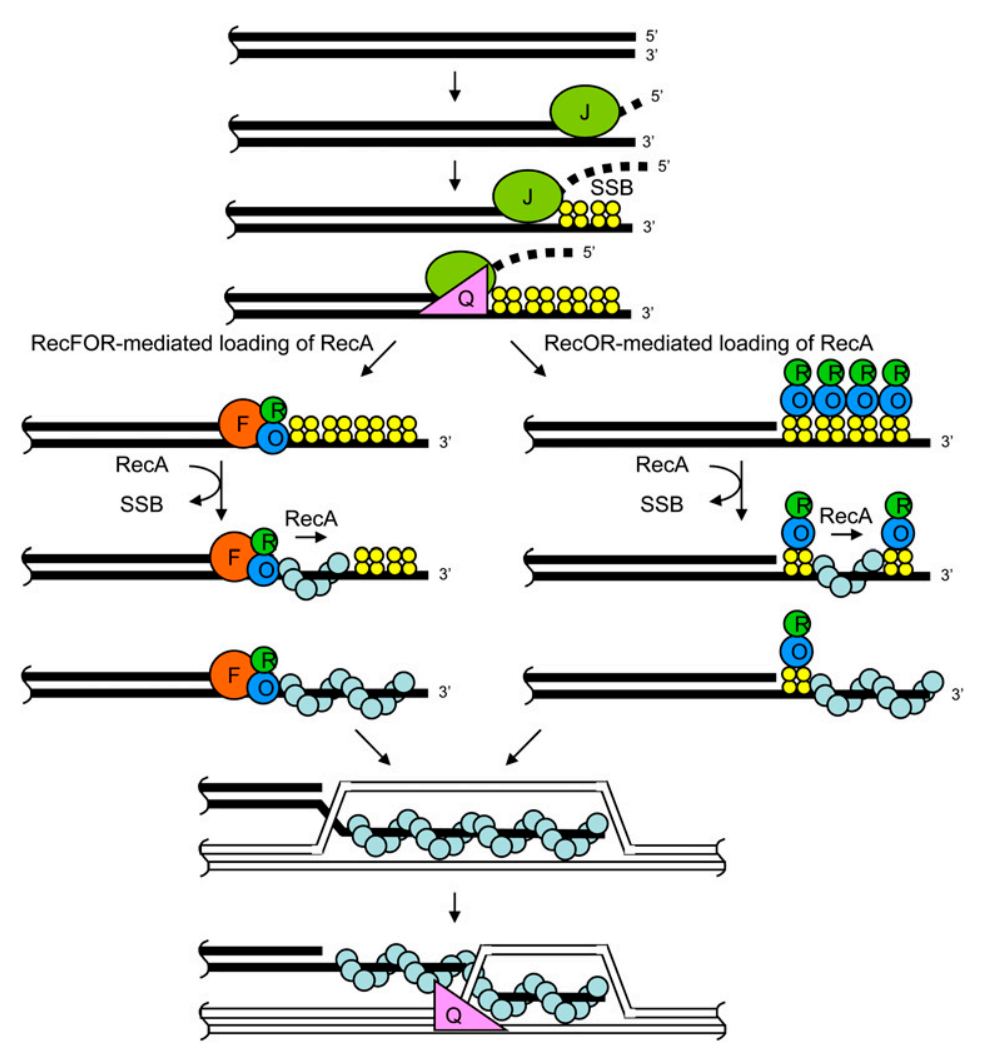

RuvABC complex, which could be augmented or antagonized by RecG (Muller and West 1994; Sharples et al. 1999); both RuvABC and RecG are capable of producing both crossover and noncrossover products, although the partitioning of their functions is not fully understood (Grove et al. 2008). The precise function of RecN remains to be determined but, as was established in B. subtilis, it appears early at a DSB implying a role in the bridging of the unprocessed broken DNA ends, either intra- or intermolecularly; RecN is a ssDNA-dependent ATPase that binds to a DSB (Sanchez et al. 2006, 2008). In agreement, in E. coli, RecN becomes essential for DSB repair when more than one DSB occurs, suggesting that $\mathrm{RecN}$ is needed to bind to DNA ends to maintain the alignment or integrity of the broken chromosomes (Meddows et al. 2005).

Interestingly, the RecF pathway of $E$. coli bears extensive similarity to the Rad52 epistasis group of recombination proteins that were defined initially in yeast and found subsequently in other eukaryotes (Pâques and Haber 1999; Symington 2002; Spies and Kowalczykowski 2005). Many of the proteins that act in the RecF pathway have structural or functional homologs in both singleand multicellular eukaryotes. Consequently, we believe that the results presented here can be extended to the more complex biochemistry of recombinational DNA repair in eukaryotes. Rad51 is the clear homolog of RecA, and its assembly is facilitated by mediator proteins (Sung et al. 2003). The mediator protein that is functionally homologous to RecO is Rad52 (Kantake et al. 2002), and 
the proteins that are likely functionally similar to RecF and RecR are the yeast Rad55/57 complex (Fortin and Symington 2002) and the human Rad51 paralogs (Symington 2002). Furthermore, in terms of RecQ homologs, eukaryotes have at least one (Sgs1 in yeast) and up to five (RecQ1, BLM, WRN, RecQ4 [RTH], and RecQ5 in humans) (Wu and Hickson 2006); we believe that at least one of these helicases must function in a similar capacity to that described here for the bacterial RecQ. Finally, although the homolog of RecJ is not obvious, we would note that the discovery that RecJ has the capacity to resect dsDNA suggests to us that the eukaryotic Exonuclease 1 (Exol) is the functional homolog of RecJ. Recent biochemical work supports this proposition and also identifies BLM as the human RecQ homolog that participates in recombination initiation (Nimonkar et al. 2008). Furthermore, recent genetic studies and the physical analysis of DNA breaks in S. cerevisiae identified a role for Sgs1, Dna2, and Exo1 in the extensive resection of dsDNA breaks (Gravel et al. 2008; Mimitou and Symington 2008; Zhu et al. 2008), supporting our contention that RecJ and eukaryotic Exol, and RecQ, Sgs1, and BLM are functional homologs. In addition, the in vitro features of DNA resection by a DNA helicase and 5'-3' exonuclease from Pyrococcus furiosus have striking parallels to the processing of DNA ends by RecQ and RecJ described here (Hopkins and Paull 2008). Consequently, our discovery that RecJ has a dsDNA exonuclease activity that is required for, and works in conjunction with, RecQ to resect DNA brings the mechanism of dsDNA break processing into convergence for all three domains of life. We expect that when more complete biochemical reactions can be reconstituted for the eukaryotic proteins, comparable coordinated activities for these proteins will be discovered.

\section{Materials and methods}

\section{Joint molecule formation}

Standard reactions contained linear dsDNA (10 $\mu$ M nucleotides); 3 '-end-labeled EcoRI-digested pUC19) in reaction buffer (20 mM Tris acetate at $\mathrm{pH} 7.5,10 \mathrm{mM} \mathrm{Mg}[\text { acetate }]_{2}, 0.1 \mathrm{mM}$ DTT, $1 \mathrm{mM}$ phosphoenolpyruvate, $25 \mathrm{U} / \mathrm{mL}$ pyruvate kinase, $0.1 \mathrm{mg} / \mathrm{mL}$ BSA). Unless otherwise indicated, SSB protein $(3 \mu \mathrm{M})$ was added for 2 min at $30^{\circ} \mathrm{C}$, followed by (in order) RecQ (10 nM), RecF (15 $\mathrm{nM}), \operatorname{RecO}(100 \mathrm{nM}), \operatorname{Rec} \mathrm{R}(1 \mu \mathrm{M})$, RecA $(5 \mu \mathrm{M})$, and RecJ (0.02 $\mathrm{U} / \mu \mathrm{L})$ proteins; the salt in the storage buffer for protein stocks added $\sim 10 \mathrm{mM} \mathrm{NaCl}$ to the final reactions. Unless otherwise indicated, pUC1950 supercoiled dsDNA (100 $\mu \mathrm{M}$, nucleotides) was then added. A sample was removed before the reaction was started by addition of ATP $(1 \mathrm{mM})$. Two-dimensional electrophoresis was performed as described previously (Nimonkar and Boehmer 2003), with some modifications.

\section{Acknowledgments}

We thank Noriko Kantake for providing the RecO and RecR proteins initially used. We are grateful to Wolf Heyer, and to members of the Kowalczykowski laboratory for their critical reading of the manuscript. This work was supported by grants from the National Institute of Health, GM-43889 and GM-51753 to S.T.L. and GM-62653 to S.C.K., and also by the Japan Society for the Promotion of Science (JSPS) Post-Doctoral Fellowship for Research Abroad, Grants-in-Aid for Scientific Research awards from the JSPS, and by grants from the Ministry of Education, Culture, Sports, Science and Technology (MEXT) to N.H.

\section{References}

Allers T, Lichten M. 2001. Differential timing and control of noncrossover and crossover recombination during meiosis. Cell 106: 47-57.

Amundsen SK, Smith GR. 2003. Interchangeable parts of the Escherichia coli recombination machinery. Cell 112: 741-744.

Anderson DG, Kowalczykowski SC. 1997. The translocating RecBCD enzyme stimulates recombination by directing RecA protein onto ssDNA in a $\chi$-regulated manner. Cell 90: $77-86$.

Briggs GS, Mahdi AA, Weller GR, Wen Q, Lloyd RG. 2004. Interplay between DNA replication, recombination and repair based on the structure of RecG helicase. Philos Trans $R$ Soc Lond B Biol Sci 359: 49-59.

Bugreev DV, Yu X, Egelman EH, Mazin AV. 2007. Novel pro- and anti-recombination activities of the Bloom's syndrome helicase. Genes \& Dev 21: 3085-3094.

Chow KH, Courcelle J. 2004. RecO acts with RecF and RecR to protect and maintain replication forks blocked by UVinduced DNA damage in Escherichia coli. J Biol Chem 279: 3492-3496.

Clark AJ, Low KB. 1988. Pathways and systems of homologous recombination in Escherichia coli. In The recombination of genetic material (ed. KB Low), pp. 155-215. Academic Press, San Diego, CA.

Connelly JC, Leach DR. 1996. The sbcC and sbcD genes of Escherichia coli encode a nuclease involved in palindrome inviability and genetic recombination. Genes Cells 1: 285291.

Corrette-Bennett SE, Lovett ST. 1995. Enhancement of RecA strand-transfer activity by the RecJ exonuclease of Escherichia coli. I Biol Chem 270: 6881-6885.

Courcelle J, Hanawalt PC. 1999. RecQ and RecJ process blocked replication forks prior to the resumption of replication in UV-irradiated Escherichia coli. Mol Gen Genet 262: 543551.

Courcelle J, Donaldson JR, Chow KH, Courcelle CT. 2003. DNA damage-induced replication fork regression and processing in Escherichia coli. Science 299: 1064-1067.

Dixon DA, Kowalczykowski SC. 1991. Homologous pairing in vitro stimulated by the recombination hotspot, $\chi$. Cell 66: 361-371.

Fortin GS, Symington LS. 2002. Mutations in yeast Rad51 that partially bypass the requirement for $\operatorname{Rad} 55$ and $\operatorname{Rad} 57$ in DNA repair by increasing the stability of Rad51-DNA complexes. EMBO J 21: 3160-3170.

Gravel S, Chapman JR, Magill C, Jackson SP. 2008. DNA helicases Sgs1 and BLM promote DNA double-strand break resection. Genes \& Dev 22: 2767-2772.

Grove JI, Harris L, Buckman C, Lloyd RG. 2008. DNA double strand break repair and crossing over mediated by RuvABC resolvase and RecG translocase. DNA Repair (Amst) 7: 15171530.

Han ES, Cooper DL, Persky NS, Sutera VA Jr, Whitaker RD, Montello ML, Lovett ST. 2006. RecJ exonuclease: Substrates, products and interaction with SSB. Nucleic Acids Res 34: 1084-1091.

Harmon FG, Kowalczykowski SC. 1998. RecQ helicase, in concert with RecA and SSB proteins, initiates and disrupts DNA recombination. Genes \& Dev 12: 1134-1144. 
Harmon FG, Kowalczykowski SC. 2000. Coupling of DNA helicase function to DNA strand exchange activity. Methods Mol Biol 152: 75-89.

Harmon FG, Kowalczykowski SC. 2001. Biochemical characterization of the DNA helicase activity of the Escherichia coli RecQ helicase. J Biol Chem 276: 232-243.

Harmon FG, DiGate RJ, Kowalczykowski SC. 1999. RecQ helicase and topoisomerase III comprise a novel DNA strand passage function: A conserved mechanism for control of DNA recombination. Mol Cell 3: 611-620.

Harmon FG, Brockman JP, Kowalczykowski SC. 2003. RecQ helicase stimulates both DNA catenation and changes in DNA topology by topoisomerase III. J Biol Chem 278: 42668 42678.

Hopkins BB, Paull TT. 2008. The P. furiosus Mre11/Rad50 complex promotes $5^{\prime}$ strand resection at a DNA doublestrand break. Cell 135: 250-260.

Horii Z-I, Clark AJ. 1973. Genetic analysis of the recF pathway to genetic recombination in Escherichia coli K12: Isolation and characterization of mutants. J Mol Biol 80: 327-344.

Howard-Flanders P. 1975. Repair by genetic recombination in bacteria: Overview. Basic Life Sci 5A: 265-274.

Hunter N, Kleckner N. 2001. The single-end invasion: An asymmetric intermediate at the double-strand break to double-Holliday junction transition of meiotic recombination. Cell 106: 59-70.

Kantake N, Madiraju MV, Sugiyama T, Kowalczykowski SC. 2002. Escherichia coli RecO protein anneals ssDNA complexed with its cognate ssDNA-binding protein: A common step in genetic recombination. Proc Natl Acad Sci 99: 1532715332.

Kidane D, Graumann PL. 2005. Dynamic formation of RecA filaments at DNA double strand break repair centers in live cells. J Cell Biol 170: 357-366.

Kolodner R, Fishel RA, Howard M. 1985. Genetic recombination of bacterial plasmid DNA: Effect of recF pathway mutations on plasmid recombination in Escherichia coli. I Bacteriol 163: 1060-1066.

Kowalczykowski SC, Clow J, Somani R, Varghese A. 1987. Effects of the Escherichia coli SSB protein on the binding of Escherichia coli RecA protein to single-stranded DNA: Demonstration of competitive binding and the lack of a specific protein-protein interaction. J Mol Biol 193: 81-95.

Kushner SR, Nagaishi H, Clark AJ. 1972. Indirect suppression of $r e c B$ and $r e c C$ mutations by exonuclease I deficiency. Proc Natl Acad Sci 69: 1366-1370.

Kuzminov A. 1999. Recombinational repair of DNA damage in Escherichia coli and bacteriophage $\lambda$. Microbiol Mol Biol Rev 63: $751-813$.

Lavery PE, Kowalczykowski SC. 1992. Biochemical basis of the constitutive repressor cleavage activity of recA730 protein: A comparison to recA441 and recA803 proteins. I Biol Chem 267: 20648-20658.

Liu YH, Cheng AJ, Wang TC. 1998. Involvement of recF, recO, and recR genes in UV-radiation mutagenesis of Escherichia coli. J Bacteriol 180: 1766-1770.

Lloyd RG, Low KB. 1996. Homologous recombination. In Escherichia coli and Salmonella: Cellular and molecular niology (ed. FC Neidhardt), pp. 2236-2255. ASM Press, Washington, DC.

Lloyd RG, Buckman C, Benson FE. 1987a. Genetic analysis of conjugational recombination in Escherichia coli K12 strains deficient in RecBCD enzyme. I Gen Microbiol 133: 2531 2538.

Lloyd RG, Evans NP, Buckman C. 1987b. Formation of recombinant lacZ+ DNA in conjugational crosses with a $\operatorname{rec} B$ mutant of Escherichia coli $\mathrm{K} 12$ depends on recF, recJ, and recO. Mol Gen Genet 209: 135-141.

Lovett ST, Clark AJ. 1983. Genetic analysis of regulation of the RecF pathway of recombination in Escherichia coli K-12. I Bacteriol 153: 1471-1478.

Lovett ST, Clark AJ. 1984. Genetic analysis of the recJ gene of Escherichia coli K-12. J Bacteriol 157: 190-196.

Lovett ST, Sutera VA Jr. 1995. Suppression of recJ exonuclease mutants of Escherichia coli by alterations in DNA helicases II (uvrD) and IV (helD). Genetics 140: 27-45.

Luisi-DeLuca C, Lovett ST, Kolodner RD. 1989. Genetic and physical analysis of plasmid recombination in $\mathrm{rec} B$ recC $s b c B$ and $r e c B$ recC sbcA Escherichia coli K-12 mutants. Genetics 122: 269-278.

Madiraju MVVS, Clark AJ. 1990. Use of recA803, a partial suppressor of $r e c F$, to analyze the effects of the mutant $S s b$ (single-stranded DNA-binding) proteins in vivo and in vitro. Mol Gen Genet 224: 129-135.

Madiraju MVVS, Lavery PE, Kowalczykowski SC, Clark AJ. 1992. Enzymatic properties of the RecA803 protein, a partial suppressor of recF mutations. Biochemistry 31: 10529-10535.

Mahdi AA, Lloyd RG. 1989. Identification of the recR locus of Escherichia coli K-12 and analysis of its role in recombination and DNA repair. Mol Gen Genet 216: 503-510.

Meddows TR, Savory AP, Grove JI, Moore T, Lloyd RG. 2005. RecN protein and transcription factor DksA combine to promote faithful recombinational repair of DNA doublestrand breaks. Mol Microbiol 57: 97-110.

Mendonca VM, Kaiser-Rogers K, Matson SW. 1993. Double helicase II (uvrD)-helicase IV (helD) deletion mutants are defective in the recombination pathways of Escherichia coli. I Bacteriol 175: 4641-4651.

Mendonca VM, Klepin HD, Matson SW. 1995. DNA helicases in recombination and repair: Construction of a $\Delta u v r D \Delta$ helD $\Delta r e c Q$ mutant deficient in recombination and repair. $I$ Bacteriol 177: 1326-1335.

Michel B, Baharoglu Z, Lestini R. 2007. Genetics of recombination in the model bacterium Escherichia coli. In Molecular genetics of recombination (eds. A Aguilera and R Rothstein), pp. 1-26. Springer, Berlin.

Mimitou EP, Symington LS. 2008. Sae2, Exo1 and Sgs1 collaborate in DNA double-strand break processing. Nature 455: 770-774.

Morimatsu K, Kowalczykowski SC. 2003. RecFOR proteins load RecA protein onto gapped DNA to accelerate DNA strand exchange: A universal step of recombinational repair. Mol Cell 11: 1337-1347.

Muller B, West SC. 1994. Processing of Holliday junctions by the Escherichia coli RuvA, RuvB, RuvC and RecG proteins. Experientia 50: 216-222.

Nakayama H, Nakayama K, Nakayama R, Irino N, Nakayama Y, Hanawalt PC. 1984. Isolation and genetic characterization of a thymineless death-resistant mutant of Escherichia coli K-12: Identification of a new mutation (recQ1) that blocks the recF recombination pathway. Mol Gen Genet 195: 474480.

Nimonkar AV, Boehmer PE. 2003. Reconstitution of recombination-dependent DNA synthesis in herpes simplex virus 1 . Proc Nat1 Acad Sci 100: 10201-10206.

Nimonkar AV, Ozsoy AZ, Genschel J, Modrich P, Kowalczykowski SC. 2008. Human exonuclease 1 and BLM helicase interact to resect DNA and initiate DNA repair. Proc Natl Acad Sci 105: 16906-16911.

Pâques F, Haber JE. 1999. Multiple pathways of recombination induced by double-strand breaks in Saccharomyces cerevisiae. Microbiol Mol Biol Rev 63: 349-404. 
Rocha EP, Cornet E, Michel B. 2005. Comparative and evolutionary analysis of the bacterial homologous recombination systems. PLoS Genet 1: e15. doi: 10.1371/journal.pgen.0010015.

Sanchez H, Alonso JC. 2005. Bacillus subtilis RecN binds and protects 3 '-single-stranded DNA extensions in the presence of ATP. Nucleic Acids Res 33: 2343-2350.

Sanchez H, Kidane D, Castillo Cozar M, Graumann PL, Alonso JC. 2006. Recruitment of Bacillus subtilis RecN to DNA double-strand breaks in the absence of DNA end processing. $I$ Bacteriol 188: 353-360.

Sanchez H, Carrasco B, Ayora S, Alonso J. 2007. Homologous recombination in low $\mathrm{dC}+\mathrm{dG}$ Gram-positive bacteria. In Molecular genetics of recombination (eds. A Aguilera and R Rothstein), pp. 27-52. Springer, Berlin.

Sanchez H, Cardenas PP, Yoshimura SH, Takeyasu K, Alonso JC. 2008. Dynamic structures of Bacillus subtilis RecN-DNA complexes. Nucleic Acids Res 36: 110-120.

Sandler SJ, Clark AJ. 1994. RecOR suppression of recF mutant phenotypes in Escherichia coli K-12. I Bacteriol 176: 36613672.

Sawitzke JA, Stahl FW. 1992. Phage $\lambda$ has an analog of Escherichia coli recO, recR and recF genes. Genetics 130: 7-16.

Sharples GJ, Ingleston SM, Lloyd RG. 1999. Holliday junction processing in bacteria: Insights from the evolutionary conservation of RuvABC, RecG, and RusA. I Bacteriol 181: 5543-5550.

Spies M, Kowalczykowski SC. 2005. Homologous recombination by RecBCD and RecF pathways. In The bacterial chromosome (ed. NP Higgins), pp. 389-403. ASM Press, Washington, DC.

Sung P. 1997. Yeast Rad55 and Rad57 proteins form a heterodimer that functions with replication protein A to promote DNA strand exchange by Rad51 recombinase. Genes \& Dev 11: 1111-1121.

Sung P, Krejci L, Van Komen S, Sehorn MG. 2003. Rad51 recombinase and recombination mediators. I Biol Chem 278: 42729-42732.

Symington LS. 2002. Role of RAD52 epistasis group genes in homologous recombination and double-strand break repair. Microbiol Mol Biol Rev 66: 630-670.

Thoms B, Wackernagel W. 1988. Suppression of the UV-sensitive phenotype of Escherichia coli recF mutants by recA(Srf) and recA(Tif) mutations requires rec $T^{+}$. I Bacteriol 170: 36753681.

Thoms B, Borchers I, Wackernagel W. 2008. Effects of singlestrand DNases ExoI, RecJ, ExoVII, and SbcCD on homologous recombination of recBCD+ strains of Escherichia coli and roles of SbcB15 and XonA2 ExoI mutant enzymes. I Bacteriol 190: 179-192.

Umezu K, Kolodner RD. 1994. Protein interactions in genetic recombination in Escherichia coli. Interactions involving $\mathrm{RecO}$ and RecR overcome the inhibition of RecA by singlestranded DNA-binding protein. I Biol Chem 269: 3000530013.

Umezu K, Nakayama K, Nakayama H. 1990. Escherichia coli RecQ protein is a DNA helicase. Proc Natl Acad Sci 87: 5363-5367.

Umezu K, Chi NW, Kolodner RD. 1993. Biochemical interaction of the Escherichia coli $\mathrm{RecF}$, RecO, and RecR proteins with RecA protein and single-stranded DNA binding protein. Proc Natl Acad Sci 90: 3875-3879.

Viswanathan M, Lacirignola JT, Hurley RL, Lovett ST. 2000. A novel mutational hotspot in a natural quasipalindrome in Escherichia coli. J Mol Biol 302: 553-564.

Volkert MR, Hartke MA. 1984. Suppression of Escherichia coli recF mutations by recA-linked srfA mutations. I Bacteriol 157: 498-506.
Wang T-CV, Chang HY, Hung JL. 1993. Cosuppression of recF, reck and recO mutations by mutant recA alleles in Escherichia coli cells. Mutat Res 294: 157-166.

Wu L, Hickson ID. 2003. The Bloom's syndrome helicase suppresses crossing over during homologous recombination. Nature 426: 870-874.

Wu L, Hickson ID. 2006. DNA helicases required for homologous recombination and repair of damaged replication forks. Annu Rev Genet 40: 279-306.

Zhu Z, Chung WH, Shim EY, Lee SE, Ira G. 2008. Sgs1 helicase and two nucleases Dna2 and Exo1 resect DNA double-strand break ends. Cell 134: 981-994. 


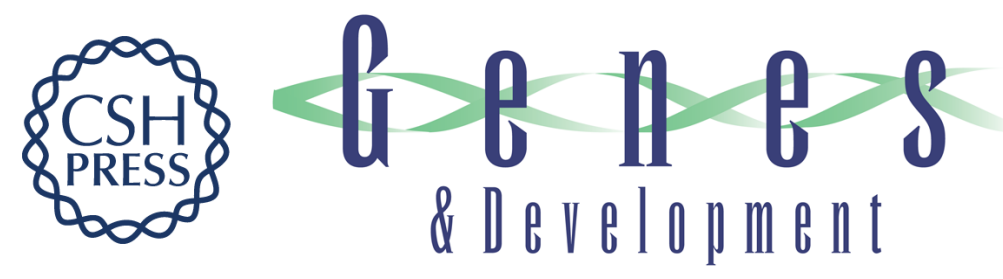

\section{Reconstitution of initial steps of dsDNA break repair by the RecF pathway of E. coli}

Naofumi Handa, Katsumi Morimatsu, Susan T. Lovett, et al.

Genes Dev. 2009, 23:

Access the most recent version at doi:10.1101/gad.1780709

Supplemental http://genesdev.cshlp.org/content/suppl/2009/05/07/23.10.1234.DC1
Material

References This article cites 72 articles, 38 of which can be accessed free at:

http://genesdev.cshlp.org/content/23/10/1234.full.html\#ref-list-1

License

Email Alerting

Receive free email alerts when new articles cite this article - sign up in the box at the top

Service

right corner of the article or click here.

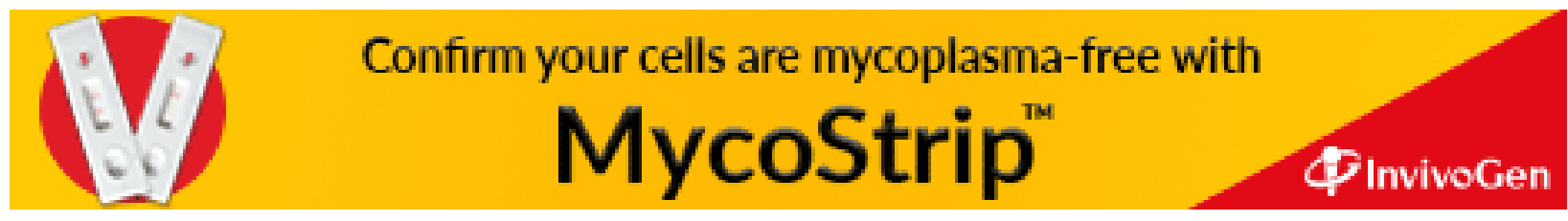

